\title{
How can we best prolong life? Benefits of coronary risk factor reduction in non-diabetic and diabetic subjects
}

\author{
John S Yudkin
}

\section{Abstract}

Objective-To compare the theoretical benefits of different approaches to reduce risk factors for coronary heart disease in subjects at risk.

Design-The results of findings from metaanalyses of intervention studies on cause specific mortality and of observational studies on smokers and ex-smokers were applied to observational data on 10 year cause specific mortality derived from the multiple risk factor intervention trial. Lifetable analyses were used to estimate gains in life expectancy.

Subjects-Diabetic and non-diabetic men initially 35-57 years of age.

Main outcome measures-10 year mortality from coronary heart disease, 10 year total mortality, man years of intervention to prevent one death and one death from coronary heart disease, gain in life expectancy, and drug costs per year of additional life in diabetic and non-diabetic men of 45.

Results-In non-diabetic men a 10 year mortality from coronary heart disease of 14.4 per 1000 would be reduced by a mean of $0.58,0.82,2 \cdot 64$, and 2.74 per 1000 by antihypertensive treatment, lowering cholesterol concentration, taking aspirin, and stopping smoking respectively; a 10 year total mortality of $44 \cdot 1$ per 1000 would fall by a mean of $1 \cdot 06,5 \cdot 16$, and 8.65 per 1000 with antihypertensive and aspirin treatment and stopping smoking respectively and increased by a mean of 0.07 per 1000 with the lowering, of cholesterol concentration. In diabetic men the reductions in mortality from coronary heart disease would be between three and five times greater, and total mortality would show mean reductions of $5.81,0.56,16.17$, and 20.84 per 1000 respectively, with all interventions of significant benefit except the lowering of cholesterol concentration. Between 2400 and 3800 man years of pharmacological intervention were calculated as being necessary to prevent one death from coronary heart disease in a non-diabetic man, and between 800 and 1200 man years in a diabetic man. The loss of life expectancy associated with smoking and hypertension is greater than that accruing from hypercholesterolaemia, but stopping smoking would prolong life by a mean of around four years in a 45 year old non-diabetic man and three years in a diabetic man, whereas aspirin and antihypertensive treatment would provide approximately one year of additional life expectancy in both categories.

Conclusions-Studies to date have shown little impact of drugs that lower cholesterol concentration and blood pressure on either coronary heart disease or total mortality. Although new treatments for hypercholesterolaemia and hypertension might help prevent coronary heart disease, other approaches to reduce the burden of premature death are required.
Introduction

Tackling the burden of coronary heart disease needs both population strategies, based on reducing the overall levels of risk factors in populations, and interventional approaches for those at the upper end of the risk factor distribution. ${ }^{1}$ Calculations of the efficacy of population approaches have estimated gains in life expectancy of between 0.4 and $1 \cdot 1$ years for different strategies applied to 35 year olds. ${ }^{2}$ Such studies have estimated benefit by calculating mortality before and after statistical removal of the adverse effect of the risk factor, ${ }^{2-4}$ but in reality treated hypertensive subjects or ex-smokers remain at greater risk than normotensive subjects or those who have never smoked. To my knowledge, no estimates exist comparing the likely benefits of different targeted interventions in people at high risk.

Several recent meta-analyses have assessed the effects of treating hypertension ${ }^{5}$ and hypercholesterolaemia $^{6-8}$ and of aspirin treatment ${ }^{9}$ on both cardiovascular and other causes of death. These analyses have provided estimates, with confidence intervals, of proportional changes in cause specific mortality resulting from the effects of the interventions. If these interventions are assumed to have similar effects in people at high risk in the general population measurement and comparison of the likely effects of different interventional approaches should be possible.

Diabetic subjects are at high risk of coronary heart disease and stroke, and risk factors, such as serum cholesterol concentration, blood pressure, and smoking, are also important in diabetes. ${ }^{10-12}$ Large intervention studies of risk factor reduction have not been done in diabetic subjects. Indeed, only one of the studies in which people with diabetes have been included, the hypertension detection and follow up program, has reported the effects of intervention separately in diabetic and non-diabetic participants ${ }^{13}$; similar proportional effects on outcome were found in the two groups. It might, therefore, be valid to use similar approaches to those outlined above to estimate the effects of intervention in a group at high risk of cardiovascular disease.

Detailed observations on cause specific 10 year mortality are available for 342815 non-diabetic and 5163 diabetic men screened for the multiple risk factor intervention trial who were aged 35-57 and free of myocardial infarction at baseline. I used these data as the baseline for calculations comparing the benefits of four different approaches to reducing cardiovascular risk in the population: lowering cholesterol concentration and blood pressure, stopping smoking, and primary prevention with the antiplatelet drug aspirin.

\section{Methods}

The multiple risk factor intervention trial screened 347978 men aged 35-57 who were free of myocardial
John S Yudkin, professor of medicine

BMF 1993;306:1313-8 
infarction at baseline, ${ }^{12} 14$ with assessment of blood pressure while sitting, serum cholesterol concentration, and smoking state. Published data on six year mortality according to the value of baseline variables ${ }^{12}$ have been supplemented by similar figures for 10 year mortality according to the quintile of baseline cholesterol concentration and systolic blood pressure and smoking state (O Vaccaro, 26th annual meeting of the European Diabetes Epidemiology Study Group, Lund, 1991). Causes of death were grouped as coronary heart disease; stroke; vascular (non-coronary and non-stroke); cancer; and non-vascular, noncancer. Because of the possibility that lowering cholesterol concentration affects the risk of accidental death and suicide, ${ }^{75-17}$ these two causes of death were grouped and considered separately in calculations on the effects of lowering cholesterol concentration. At the 10 year follow up of the multiple risk factor intervention trial 15486 non-diabetic men and 801 diabetic men had died, and I have used these figures, with no error assumed, as the baseline rate with which to calculate the theoretical benefits of interventions.

I assessed the proportionate effects of different interventions on each cause of death from metaanalyses of studies of lowering blood pressures and cholesterol concentration ( $R$ Collins, personal communication) ${ }^{67}$ and of the effects of aspirin (Antiplatelet Trialists' Collaboration, personal communication), ${ }^{9}$ the effects of lowering cholesterol concentration and of aspirin being updated from published figures. The mean reductions in blood pressure and cholesterol concentration in these studies were around $5-6 \mathrm{~mm} \mathrm{Hg}$ and $0.6 \mathrm{mmol} / \mathrm{l}$ respectively. Because the proportionate effects of lowering cholesterol concentration and of aspirin treatment were not significantly different in primary and secondary prevention studies ( $R$ Collins and Antiplatelet Trialists' Collaboration, personal communications) $^{89} \mathrm{I}$ used the meta-analyses of all trials combined for the calculations presented in the tables, although calculations were also done using data from primary prevention studies alone. Because intervention studies on smoking have concerned only small numbers of subjects ${ }^{18}$ the effects of stopping smoking on different causes of death were calculated by comparing the observations on mortality in smokers and exsmokers among the 89691 men of the American veterans' study. ${ }^{19}$ For all interventions, I have assumed that the proportional effects of interventions on mortality are constant for the whole period of intervention, although the full benefits of reducing a risk factor might take several years to become apparent ( $\mathrm{R}$ Collins, personal communication)..$^{20}$

I estimated the effects of a theoretical intervention in men in the top fifth of the distribution of total cholesterol concentration $(\geqslant 6.3 \mathrm{mmol} / \mathrm{l})$ and of systolic blood pressure ( $\geqslant 142 \mathrm{~mm} \mathrm{Hg}$ ). The proportionate benefits of treating hypertension have been taken from a meta-analysis of studies of hypertension in which diastolic blood pressure was the criterion for treatment. ${ }^{5}$ In my analysis, however, systolic blood pressure was the criterion for intervention because of the recently shown efficacy of treating isolated systolic hypertension. ${ }^{21}$ Results are similar if diastolic blood pressure is used instead. The effects of stopping smoking were calculated by applying the proportionate differences in mortality between smokers and exsmokers, although, if anything, this might produce bias against the benefits of stopping smoking because it includes people who stop smoking for health reasons. The benefits of aspirin treatment were calculated by assuming that all subjects were treated.

The change, and standard deviation in change, for each cause of death were calculated for 1000 diabetic and 1000 non-diabetic men, dichotomised in the case of cholesterol concentration and blood pressure as

\section{Necessary assumptions for validity of} estimates

Non-diabetic and diabetic subjects

- Meta-analyses reliably estimate effects of interventions

- Benefits and risks of interventions are similar in intervention studies and in treating populations

- Proportional effects of interventions on outcome are constant over time

- Newer agents have similar effects on cause specific mortality to drugs previously used in major studies

- Benefits and risks are similar in primary and secondary intervention trials (but data have been calculated for primary prevention studies alone)

\section{Diabetic subjects}

- Risk factor has same proportional effect on cause specific mortality as in non-diabetic subjects

- Intervention has same proportional effects on risk factor, and on cause specific mortality, as in nondiabetic subjects

being either in the top fifth or in the remaining group of the total population distribution, and in the case of smoking as being ex-smokers, non-smokers, or smokers. The absolute reduction or increase in numbers of deaths and the standard deviations were then used to calculate the theoretical 10 year mortality in the total population; $95 \%$ confidence intervals were derived from these standard deviations.

The increases in median life expectancy were calculated by life table methods, using actuarial data showing that a British non-diabetic man of 45 would have a median additional life expectancy of 29.9 years. ${ }^{22}$ The value $q_{x}$, representing the probability of dying in each year, for men of each age from 45 years was obtained from these life tables. ${ }^{22}$ This value was then multiplied by the ratio of 10 year total mortality in a stratum of risk (or that calculated with an intervention) divided by the 10 year mortality observed in the multiple risk factor intervention trial for nondiabetic men (44.1 per 1000; O Vaccaro, 26th annual meeting of the European Diabetes Epidemiology Study Group, Lund, 1991) (see tables I and II). These calculations assume that the proportionate changes in total mortality for each intervention operate in each year of follow up. The calculations of years of treatment per additional year of life were derived by dividing the estimated life expectancy for a man of 45 with a particular intervention by the gain in life expectancy resulting from that intervention. Cost was estimated from the prices listed in the British National Formulary. ${ }^{23}$

\section{Necessary assumptions}

Assumptions are outlined in the box. Differences in compliance during clinical studies and in real life might overestimate the possible benefits of clinical trials. However, the full effects of reducing a risk factor on mortality from coronary heart disease may become apparent only after several years of intervention. ${ }^{20}$ Newer drugs might achieve greater reductions in cholesterol concentration, and perhaps blood pressure, with consequently greater possible benefits, although this remains to be proved.

- Two other assumptions are necessary to be able to estimate likely benefits in diabetic subjects. Firstly, each risk factor is assumed to have the same proportionate effects in diabetic and non-diabetic subjects, although data from the multiple risk factor intervention trial suggest that the odds ratios for serum 
cholesterol concentration and blood pressure are lower in diabetic than in non-diabetic subjects. ${ }^{12}$ If the adverse effects of a risk factor are less in diabetic subjects the proportionate benefits of lowering that risk factor may be less than I have used in these calculations. The other necessary assumption is that there are no disease specific benefits or hazards of particular interventions in the diabetic group. Antihypertensive treatment might be more beneficial in diabetic subjects with proteinuria, ${ }^{24}$ or the presence of asymptomatic coronary heart disease might increase the risks of reducing blood pressure in diabetic patients because of the putative J shaped curve. ${ }^{25}{ }^{26}$ Diuretic treatment may also be associated with increased mortality from cardiovascular disease in diabetic patients. $^{27}$

\section{Results}

Table I shows the approach used in this study. From the observations of cause specific mortality by baseline characteristics in the 347978 non-diabetic subjects of the multiple risk factor intervention trial and the prevalence of hypertension in these subjects (section A) (O Vaccaro, 26th annual meeting of the European Diabetes Epidemiology Study Group, Lund, 1991), the number of deaths was calculated in each stratum for each cause (section B). In section $C$ the findings of the meta-analysis on the efficacy of antihypertensive treatment according to cause of death are given. ${ }^{5}$ If these proportionate changes in mortality are applied to the calculated numbers of deaths in the hypertensive stratum of subjects the expected numbers of deaths with treatment (section D) and the reductions in the numbers of deaths (section $\mathrm{E}$ ) can be derived. In the hypertensive group treatment results in a mean reduction of $11.1 \%$ in deaths from coronary heart disease $(0.58$ of 5.2$)$ and an overall reduction of $8.0 \%$ in deaths $(1.06$ of 13.2$)$, but this corresponds to only a mean reduction of $4 \%$ in deaths from coronary heart disease $(0.58$ of 14.4$)$ and reduction of $2.4 \%$ in overall mortality $(1.06$ of 44.1$)$ for the population as a whole. If these reductions are achieved as a result of treating 194 hypertensive men for 10 years 3345 (95\% confidence interval 1564 to $\infty$ ) man years of antihypertensive treatment would be needed to prevent one death from coronary heart disease, 6929 (5389 to 10778) to prevent one stroke death, and $1830(862$ to $\infty)$ to prevent one death (table II). Because the confidence intervals of effect on mortality encompass zero the duration of treatment per death prevented reaches infinity.

Identical approaches are applied to mortality data on diabetic and non-diabetic subjects in table II. Although my chosen cut off point for systolic blood pressure, $142 \mathrm{~mm} \mathrm{Hg}$, represents the top quintile in the subjects of the multiple risk factor intervention trial as a whole, some $36 \%$ of diabetic subjects have higher blood pressures compared with $19 \%$ of nondiabetic subjects. By the nature of the exercise, the same proportionate changes apply to each individual cause of death, but in the diabetic subjects the mean reduction in overall mortality with antihypertensive treatment calculates as $4 \cdot 4 \%(5 \cdot 81$ of $131 \cdot 5)$, compared with $2.4 \%(1.06$ of 44.1$)$ in the non-diabetic subjects,

TABLE I-Calculated effects of antihypertensive treatment for patients with systolic blood pressure $\geqslant 142 \mathrm{~mm} \mathrm{Hg}$ on cause specific mortality in 1000 men aged 35-57 without diabetes or history of myocardial infarction *

\begin{tabular}{|c|c|c|c|c|c|}
\hline & \multicolumn{5}{|c|}{ Age adjusted mortality per 1000 from: } \\
\hline & $\begin{array}{l}\text { Coronary heart } \\
\text { disease }\end{array}$ & Stroke & $\begin{array}{c}\text { Other } \\
\text { vascular }\end{array}$ & $\begin{array}{c}\text { Non- } \\
\text { vascular }\end{array}$ & Total \\
\hline \multicolumn{6}{|c|}{ (A) Mortality data } \\
\hline $\begin{array}{l}\text { Systolic pressure (mm Hg): } \\
\quad<142(\mathrm{~m}=806) \\
\geqslant 142(\mathrm{n}=194)\end{array}$ & $\begin{array}{l}11 \cdot 4 \\
26 \cdot 9\end{array}$ & $\begin{array}{l}1 \cdot 0 \\
3 \cdot 2\end{array}$ & $\begin{array}{l}2 \cdot 5 \\
6 \cdot 3\end{array}$ & $\begin{array}{l}23 \cdot 4 \\
32 \cdot 0\end{array}$ & $\begin{array}{l}38 \cdot 3 \\
68 \cdot 4\end{array}$ \\
\hline \multicolumn{6}{|c|}{ (B) Observed No of deaths (no treatment) } \\
\hline $\begin{array}{l}\text { Systolic pressure (mm Hg): } \\
\quad<142(n=806) \\
\geqslant 142(n=194) \\
\text { Total }(n=1000)\end{array}$ & $\begin{array}{r}9 \cdot 2 \\
5 \cdot 2 \\
14 \cdot 4\end{array}$ & $\begin{array}{l}0.8 \\
0.6 \\
1.4\end{array}$ & $\begin{array}{l}2 \cdot 0 \\
1 \cdot 2 \\
3 \cdot 2\end{array}$ & $\begin{array}{r}18 \cdot 9 \\
6 \cdot 2 \\
25 \cdot 1\end{array}$ & $\begin{array}{l}30 \cdot 9 \\
13 \cdot 2 \\
44 \cdot 1\end{array}$ \\
\hline \multicolumn{6}{|c|}{ (C) Effect of treatment in meta-analysis ${ }^{5}$} \\
\hline $\begin{array}{l}\text { Odds ratio for mortality in treated } v \text { untreated subjects } \\
95 \% \text { Confidence interval }\end{array}$ & $\begin{array}{c}0.89 \\
0.76 \text { to } 1.04\end{array}$ & $\begin{array}{c}0.55 \\
0.42 \text { to } 0.70\end{array}$ & $\begin{array}{c}0.88 \\
0.66 \text { to } 1.18\end{array}$ & $\begin{array}{c}0.99 \\
0.86 \text { to } 1 \cdot 14\end{array}$ & \\
\hline \multicolumn{6}{|c|}{ (D) Expected No of deaths with treatment of 194 subjects with systolic pressure $\geqslant 142 \mathrm{~mm} \mathrm{Hg}$} \\
\hline $\begin{array}{l}\text { Systolic pressure (mm Hg): } \\
<142 \mathrm{~mm} \mathrm{Hg}(\mathrm{n}=806) \\
\geqslant 142 \mathrm{~mm} \mathrm{Hg}(\mathrm{n}=194) \\
95 \% \text { Confidence interval } \\
\text { Total }(\mathrm{n}=1000) \\
95 \% \text { Confidence interval }\end{array}$ & $\begin{array}{c}9 \cdot 2 \\
4 \cdot 6 \\
4 \cdot 0 \text { to } 5 \cdot 4 \\
13 \cdot 8 \\
13 \cdot 2 \text { to } 14 \cdot 6\end{array}$ & $\begin{array}{c}0.8 \\
0.3 \\
0.3 \text { to } 0.4 \\
1.1 \\
1.0 \text { to } 1.2\end{array}$ & $\begin{array}{c}2.0 \\
1 \cdot 1 \\
0.8 \text { to } 1.4 \\
3.1 \\
2.8 \text { to } 3.5\end{array}$ & $\begin{array}{c}18 \cdot 9 \\
6 \cdot 1 \\
5 \cdot 3 \text { to } 7 \cdot 1 \\
25 \cdot 0 \\
24 \cdot 2 \text { to } 25 \cdot 9\end{array}$ & $\begin{array}{c}30.9 \\
12 \cdot 1 \\
10.9 \text { to } 13.3 \\
43.1 \\
41.9 \text { to } 44.3\end{array}$ \\
\hline \multicolumn{6}{|c|}{ (E) Reductions in deaths with 10 years' treatment of 194 hypertensive subjects } \\
\hline $95 \%$ Confidence interval & $\begin{array}{c}0.58 \\
-0.20 \text { to } 1 \cdot 24\end{array}$ & $\begin{array}{c}0.28 \\
0.18 \text { to } 0.36\end{array}$ & $\begin{array}{c}0.14 \\
-0.23 \text { to } 0.41\end{array}$ & $\begin{array}{c}0.06 \\
-0.78 \text { to } 0.89\end{array}$ & $\begin{array}{c}1.06 \\
-0.13 \text { to } 2 \cdot 25\end{array}$ \\
\hline
\end{tabular}

${ }^{\star}$ From multiple risk factor intervention trial (O Vaccaro, 26th annual meeting of the European Diabetes Epidemiology Study Group, Lund, 1991). ${ }^{5}$

TABLE II-Calculated effects of antihypertensive treatment for patients with systolic pressure $\geqslant 142 \mathrm{~mm} H \mathrm{Hg}$ on cause specific mortality in 1000 non-diabetic and diabetic men aged 35-57 without myocardial infarction *

\begin{tabular}{|c|c|c|c|c|c|c|c|c|c|c|}
\hline & \multicolumn{5}{|c|}{ Non-diabetic subjects $(19.4 \%) \dagger$} & \multicolumn{5}{|c|}{ Diabetic subjects (35.7\%) $\dagger$} \\
\hline & $\begin{array}{c}\text { Coronary } \\
\text { heart disease }\end{array}$ & Stroke & Other vascular & Non-vascular & Total & $\begin{array}{c}\text { Coronary } \\
\text { heart disease }\end{array}$ & Stroke & Other vascular & Non-vascular & Total \\
\hline $\begin{array}{l}\text { Deaths per } 1000 \text { without treatment } \\
\text { Reduction in deaths with treatment } \\
95 \% \text { Confidence interval } \\
\text { Patient years of treatment to prevent }\end{array}$ & $\begin{array}{c}14 \cdot 4 \\
0.58 \\
-0 \cdot 20 \text { to } 1 \cdot 24\end{array}$ & $\begin{array}{c}1.4 \\
0.28 \\
0.18 \text { to } 0.36\end{array}$ & $\begin{array}{l}3 \cdot 2 \\
0 \cdot 14 \\
-0 \cdot 23 \text { to } 0 \cdot 41\end{array}$ & $\begin{array}{c}25 \cdot 1 \\
0.06 \\
-0.78 \text { to } 0.89\end{array}$ & $\begin{array}{c}44 \cdot 1 \\
1 \cdot 06 \\
-0 \cdot 13 \text { to } 2 \cdot 25\end{array}$ & $\begin{array}{c}54.2 \\
3.03 \\
-1.04 \text { to } 6.49\end{array}$ & $\begin{array}{c}6.2 \\
1.83 \\
1 \cdot 20 \text { to } 2 \cdot 32\end{array}$ & $\begin{array}{c}10.3 \\
0.67 \\
-1.08 \text { to } 1.97\end{array}$ & $\begin{array}{c}60.8 \\
0.28 \\
-3.98 \text { to } 3.96\end{array}$ & $\begin{array}{c}131.5 \\
5.81 \\
0.03 \text { to } 11.59\end{array}$ \\
\hline $\begin{array}{l}\text { one death } \\
95 \% \text { Confidence interval }\end{array}$ & $\begin{array}{c}3345 \\
1564 \text { to } \infty\end{array}$ & $\begin{array}{c}6929 \\
5389 \text { to } 10778\end{array}$ & $\begin{array}{c}13857 \\
4128 \text { to } \infty\end{array}$ & $\begin{array}{l}32333 \\
2156 \text { to } \infty\end{array}$ & $\begin{array}{c}1830 \\
862 \text { to } \infty\end{array}$ & $\begin{array}{c}1178 \\
550 \text { to } \infty\end{array}$ & $\begin{array}{c}1951 \\
1539 \text { to } 2975\end{array}$ & $\begin{array}{c}5328 \\
1566 \text { to } \infty\end{array}$ & $\begin{array}{l}12750 \\
901 \text { to } \infty\end{array}$ & $\begin{array}{c}615 \\
308 \text { to } 119000\end{array}$ \\
\hline
\end{tabular}

^From multiple risk factor intervention trial (O Vaccaro, 26th annual meeting of the European Diabetes Epidemiology Study Group, Lund, 1991).'

†With systolic pressure $\geqslant 142 \mathrm{~mm} \mathrm{Hg}$. 
because of the higher prevalence of hypertension and the greater proportion of deaths from coronary heart disease and stroke. As a consequence, although the confidence intervals are wide, only one third of the man years of treatment are necessary to prevent one death from coronary heart disease, one death from stroke, or one overall death compared with non-diabetic subjects. Nevertheless, over 600 years of treatment are necessary to prevent one death, with a lower limit of the $95 \%$ confidence interval of 308 years of treatment.

In table III the efficacy of four different approaches for reducing coronary heart disease and total mortality are compared. The reduction in coronary heart disease and in total deaths for each intervention are calculated as in tables I and II. Antihypertensive treatment and lowering of cholesterol concentration produce only around one quarter or one third of the benefit of stopping smoking or aspirin treatment on deaths from coronary heart disease, either in non-diabetic or diabetic subjects, although confidence intervals are wide. There are, however, major differences in the calculated effects on total mortality, with aspirin and smoking cessation producing larger benefits than antihypertensive treatment or lowering cholesterol concentration, neither or which, because of the wide confidence intervals, achieves significance in the non-diabetic population. Indeed, the calculated mean effect of lowering cholesterol concentration in non-diabetic subjects is an increase in total deaths, the most beneficial limit of the $95 \%$ confidence interval being 0.78 less deaths, a $1.8 \%$ reduction. In diabetic subjects, however, the benefits of antihypertensive treatment, but not lowering cholesterol concentration, just achieve significance at the $5 \%$ level (table III).

Figure 1 shows the man years of intervention to prevent one death from coronary heart disease, one death from stroke, and one death overall in nondiabetic and diabetic subjects aged 35-57. Because of the different proportions eligible for each intervention the ranking order of benefit is different from that in table III, but for each pharmacological intervention a mean of between 2400 and 3800 man years of treatment in non-diabetic subjects, and between 800 and 1200 man years of treatment in diabetic subjects are needed to prevent one death from coronary heart disease. Antihypertensive treatment is by far the most effective treatment for preventing deaths from stroke in both groups. The duration of treatment necessary for preventing one death from any cause shows that aspirin and antihypertensive treatment are of similar benefit in both diabetic and non-diabetic subjects. Although confidence intervals are wide, treatment to lower cholesterol concentration seems to be less effective, and the confidence intervals including infinity imply uncertainty as to whether cholesterol lowering would reduce total mortality in either group. In both groups

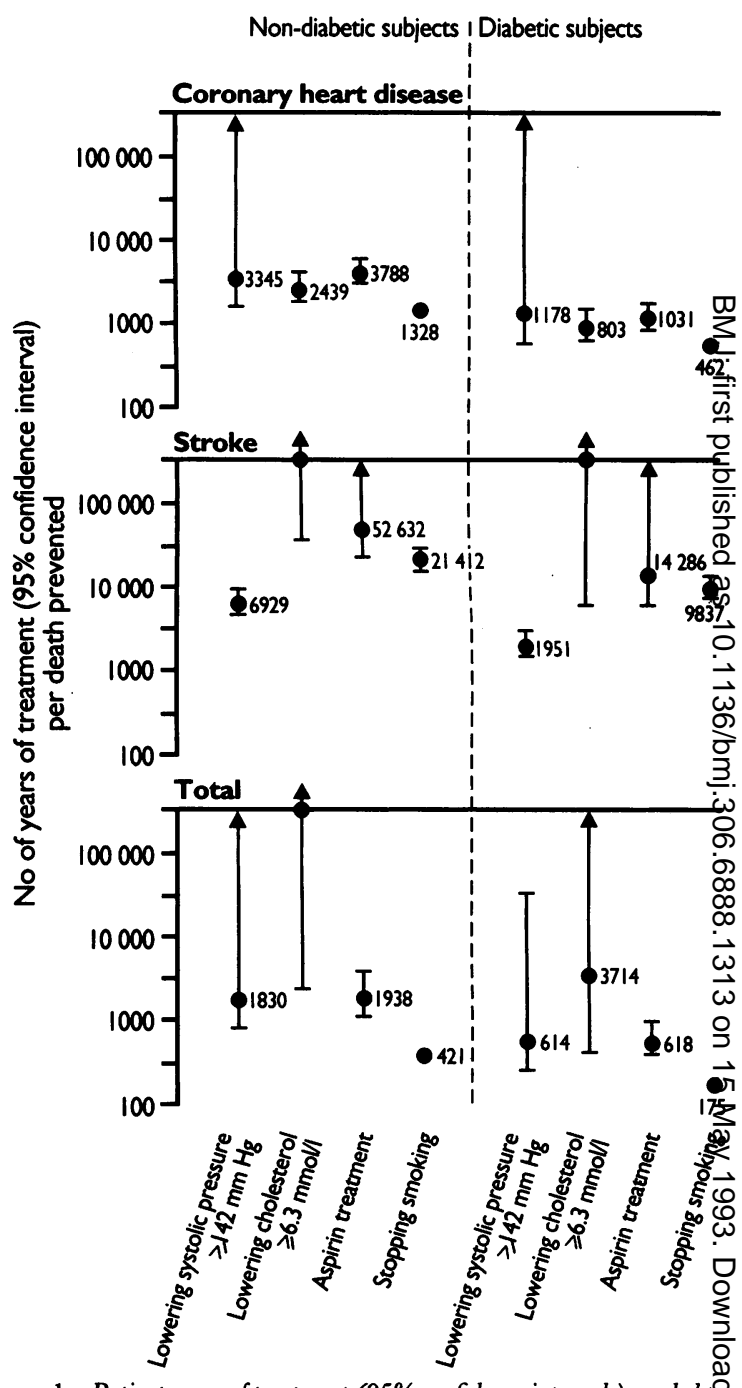

FIG 1-Patient years of treatment ( $95 \%$ confidence intervals) needed tक्ठि prevent one death from coronary heart disease death, one death fron stroke, and one death in 1000 non-diabetic and 1000 diabetic patient according to data from men aged 35-57 without myocardial infarction at baseline in multiple risk factor intervention trial ( $R$ Collins and Antiplatelet Trialists Collaboration, personal communication $O$ Vaccaro, 26th annual meeting of the European Diabetes. Epidemiology Study Group, Lund, 1991) 519

stopping smoking is substantially better than any othef intervention.

Data from meta-analysis of primary prevention triali of lowering cholesterol concentration alone ( $R$ Collins? personal communication) show little effect on the number of man years of treatment to prevent deat? from coronary heart disease (3053 $v 2439$ years), buon data from primary prevention trials for aspirin (Antis platelet Trialists' Collaboration, personal communica tion) somewhat reduces its calculated benefits ( 5555 \&

TABLE III-Calculated effects of different interventions on coronary heart disease and total mortality in 1000 non-diabetic and 1000 diabetic meg aged 35-57 without myocardial infarction *

\begin{tabular}{|c|c|c|c|c|c|c|}
\hline & \multirow[b]{2}{*}{$\begin{array}{l}\% \text { With } \\
\text { critetion for } \\
\text { treatment }\end{array}$} & \multicolumn{2}{|c|}{ Non-diabetic men } & \multirow[b]{2}{*}{$\begin{array}{l}\% \text { With } \\
\text { criterion for } \\
\text { treatment }\end{array}$} & \multicolumn{2}{|c|}{ Diabetic men } \\
\hline & & $\begin{array}{l}\text { Coronary heart } \\
\text { disease } \\
\text { deaths }\end{array}$ & $\begin{array}{l}\text { Total } \\
\text { deaths }\end{array}$ & & $\begin{array}{l}\text { Coronary heart } \\
\text { disease } \\
\text { deaths }\end{array}$ & $\begin{array}{l}\text { Total } \\
\text { deaths }\end{array}$ \\
\hline $\begin{array}{l}\text { Deaths per } 1000 \text { without treatment } \\
\text { Reductions in death with: }\end{array}$ & & $14 \cdot 4$ & $44 \cdot 1$ & & $54 \cdot 2$ & 131.5 \\
\hline Antihypertensive treatment (systolic $\geqslant 142 \mathrm{~mm} \mathrm{Hg}$ ) & $19 \cdot 4$ & 0.58 & 1.06 & 35.7 & 3.03 & $5 \cdot 81 \stackrel{<}{<}$ \\
\hline $\begin{array}{l}95 \% \text { Confidence interval } \\
\text { Cholesterol lowering treatment (from } \geqslant 6.3 \mathrm{mmol} / \mathrm{)} \text { ) } \\
95 \% \text { Confidence interval }\end{array}$ & $20 \cdot 0$ & $\begin{array}{c}-0.20 \text { to } 1.24 \\
0.82 \\
0.51 \text { to } 1.14\end{array}$ & $\begin{array}{l}-0.13 \text { to } 2.25 \\
-0.07 \\
-0.92 \text { to } 0.78\end{array}$ & $20 \cdot 8$ & $\begin{array}{c}-1.04 \text { to } 6.49 \\
2.59 \\
1.60 \text { to } 3.58\end{array}$ & $\begin{array}{c}0.03 \text { to } 11.59 \text { ○ी } \\
0.56 \text { 은 } \\
-3.80 \text { to } 4.8 \%\end{array}$ \\
\hline $\begin{array}{l}\text { Aspirin } \\
95 \% \text { Confidence interval }\end{array}$ & 100 & $\begin{array}{c}2.64 \\
1.76 \text { to } 3.53\end{array}$ & $\begin{array}{c}5 \cdot 16 \\
2 \cdot 22 \text { to } 8 \cdot 10\end{array}$ & 100 & $\begin{array}{c}9 \cdot 70 \\
6.47 \text { to } 12.90\end{array}$ & $\begin{array}{c}16 \cdot 17 \text { बे } \\
9 \cdot 66 \text { to } 22 \cdot 68 \overline{7}\end{array}$ \\
\hline $\begin{array}{l}\text { Stopping smoking } \\
95 \% \text { Confidence interval }\end{array}$ & $36 \cdot 4$ & $\begin{array}{c}2.74 \\
2.54 \text { to } 2.93\end{array}$ & $\begin{array}{c}8.65 \\
8.22 \text { to } 9.08\end{array}$ & $36 \cdot 4$ & $\begin{array}{c}7 \cdot 88 \\
7 \cdot 31 \text { to } 8 \cdot 43\end{array}$ & $\begin{array}{c}20.84 \\
19 \cdot 76 \text { to. } 21.92\end{array}$ \\
\hline
\end{tabular}

*Data from multiple risk factor intervention trial ( $R$ Collins and Antiplatelet Trialists' Collaboration, personal communications; $O$ Vaccaro, 26th annual meeting of the European Diabetes Epidemiology Study Group, Lund, 1991)." "19 


\begin{tabular}{|c|c|c|c|c|}
\hline & \multicolumn{2}{|c|}{ Non-diabetic man } & \multicolumn{2}{|c|}{ Diabetic man } \\
\hline & $\begin{array}{c}\text { Life } \\
\text { expectancy } \\
\text { (years) }\end{array}$ & $\begin{array}{c}\text { Loss with risk factor } \\
\text { or gain with } \\
\text { intervention }(95 \% \\
\text { confidence interval) } \\
\text { (years) }\end{array}$ & $\begin{array}{l}\text { Life } \\
\text { expectancy } \\
\text { (years) }\end{array}$ & $\begin{array}{c}\text { Loss with risk factor } \\
\text { or gain with } \\
\text { intervention ( } 95 \% \\
\text { confidence interval) } \\
\text { (years) }\end{array}$ \\
\hline \multirow{6}{*}{$\begin{array}{l}\text { Mean } \\
\text { Aspirin treatment } \\
\text { Smoking: } \\
\text { Non-smoker } \\
\text { Smoker } \\
\text { Ex-smoker }\end{array}$} & $29 \cdot 85$ & & $20 \cdot 30$ & \\
\hline & $31 \cdot 01$ & $1.16(0.43$ to 1.88$)$ & $21 \cdot 49$ & $1.19(0.71$ to 1.74$)$ \\
\hline & & & & \\
\hline & 32.59 & & $21 \cdot 86$ & \\
\hline & $25 \cdot 06$ & . $\quad-7.53$ & $17 \cdot 58$ & $-4 \cdot 28$ \\
\hline & 28.90 & 3.84 (3.68 to 4.04$)$ & 20.97 & 3.39 (3.18 to 3.63$)$ \\
\hline \multicolumn{5}{|c|}{ Cholesterol (mmol/h): } \\
\hline$<6.3$ & $30 \cdot 35$ & & $20 \cdot 88$ & \\
\hline$\geqslant 6.3$ & 27.87 & $-2 \cdot 48$ & $18 \cdot 10$ & -2.78 \\
\hline Lowering $\geqslant 6.3$ & 27.86 & $-0.01(-0.78$ to 0.66$)$ & $18 \cdot 24$ & $0.14(-0.92$ to 1.28$)$ \\
\hline \multicolumn{5}{|c|}{ Systolic blood pressure $(\mathrm{mm} \mathrm{Hg})$ : } \\
\hline$<142$ & $30 \cdot 90$ & & 22.03 & \\
\hline$\geqslant 142$ & $25 \cdot 50$ & -5.40 & $17 \cdot 19$ & $-4 \cdot 84$ \\
\hline Lowering $\geqslant 142$ & 26.33 & $9.83(-0.07$ to 1.79$)$ & 17.92 & $0.73(0.01$ to 1.61$)$ \\
\hline
\end{tabular}

*Screened at baseline of multiple risk factor intervention trial ( $R$ Collins and Antiplatelet Trialists' Collaboration, personal communications; O Vaccaro, 26th annual meeting of the European Diabetes Epidemiology Study Group, Lund, 1991). .922 were below these cut off levels without treatment (O Vaccaro, 26th annual meeting of the European Diabetes Epidemiology Study Group, Lund, 1991). The corresponding figures for diabetic subjects are a fall from $54 \cdot 2$ per 1000 to $39 \cdot 2$ per 1000 , compared with a mortality of 22.4 per 1000 in those with low risk values at screening. Thus, even at the expense of a pharmacological intervention for $89 \%$ of the nondiabetic and $93 \%$ of the diabetic population, only just over one third of the excess risk of coronary heart disease mortality attributed to these three risk factors is reversible using the treatments so far studied in major intervention trials.

\section{Discussion}

I calculated the benefits of risk factor interventions by using the observations on the actual effects of these interventions, rather than by assuming full reversibility, as is implicit in methods which calculate benefit by removing the adverse effect of the risk factor on mortality. ${ }^{24}$ The main assumption used in this approach is the validity of data derived from metaanalyses. Thompson and Pocock have analysed the problems of meta-analysis, including the criteria by which individual studies are included, and the validity of combining studies using different patient characteristics and study design; they conclude that it "may be unrealistic to imagine that it will produce simple statistical answers to complex clinical problems."28 It is, nevertheless, a means of measuring the probable size of a treatment effect. The calculations on smoking used observational data, but recent evidence suggests that these benefits may have been underestimated. ${ }^{29}$

The main assumptions which might be questioned are the validity of expecting benefits observed in clinical trials to be found in everyday clinical practice when asymptomatic risk factors are treated over 10 or more years. Conversely, newer agents might better
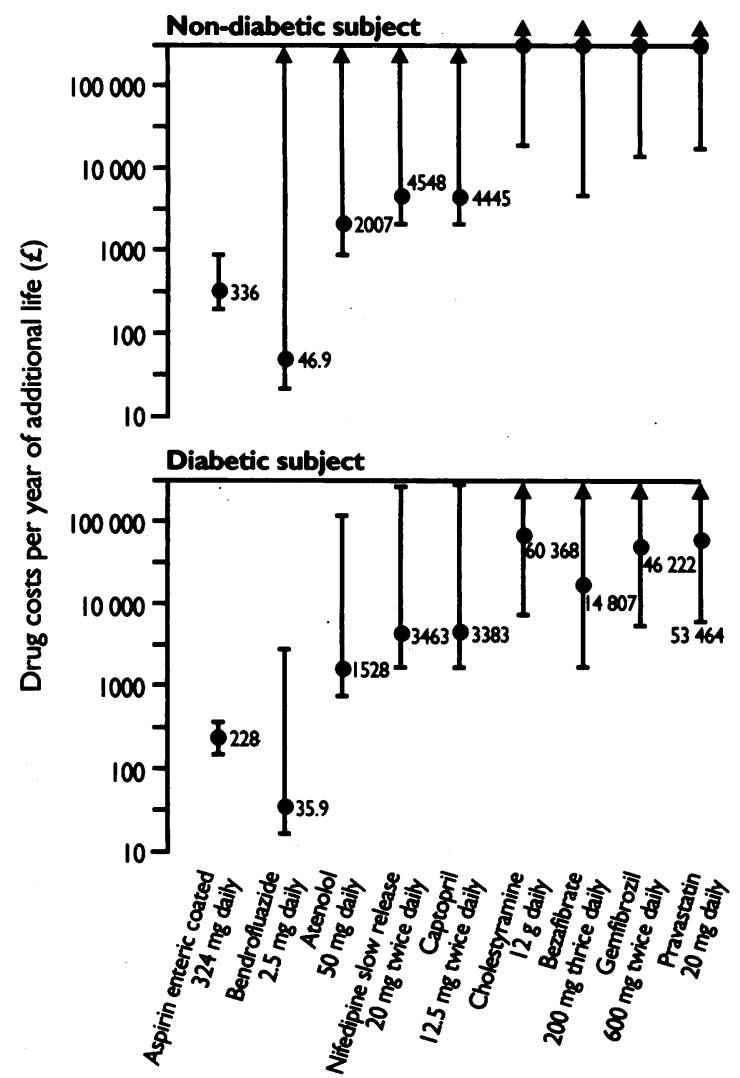

FIG 2-Estimated drug costs ( $95 \%$ confidence intervals) for one year of additional life expectancy for a non-diabetic or diabetic man of 45 screened for the multiple risk factor intervention trial study and without myocardial infarction at baseline ( $R$ Collins and Antiplatelet Trialists' Collaboration, personal communications) $)^{1922}$ 
reduce risk factors than those currently available, perhaps without deleterious effects on other risk factors such as insulin resistance or lipid concentrations. There are, nevertheless, hazards in extrapolating the effects on outcome from the effects on risk factors. The point needs re-emphasising that thiazides and $\beta$ blockers for hypertension prevent around twice as many strokes as myocardial infarctions ${ }^{50}$ so that any gains of newer agents in terms of risk factors for coronary heart disease need proving for total mortality. The absolute benefits calculated for diabetic subjects may have been overestimated if, as seems probable, the odds ratios for any level of risk factor are smaller in a diabetic than a non-diabetic population. ${ }^{12}$ Nevertheless, the absolute benefits of reducing risk factors in diabetes could be tested only in a randomised prospective intervention study. ${ }^{31}$

I have not calculated morbidity as the data have not permitted calculations of the possible benefits of nonfatal myocardial infarction or strokes. The Medical Research Council mild hypertension study showed that 850 person-years of treatment of mild hypertension is needed to prevent one non-fatal stroke, ${ }^{32}$ and this figure would probably be around $250-300$ person years of treatment for a mildly hypertensive diabetic patient. Given that the physical, psychological, and social impacts of non-fatal strokes are usually much greater than those of non-fatal myocardial infarctions, these figures should be considered alongside those in table IV and figure 1 when the possible benefits of the different interventions are considered.

The poor efficacy of all pharmacological interventions is the consequence of three main considerations of the role of risk factors. Firstly, although the risks of coronary heart disease are increased by raised levels of any risk factor, most deaths occur in subjects at low level of risk: people in the top $15 \%$ of the distribution of a risk score for coronary heart disease risk provided only $32 \%$ of cases. ${ }^{33}$ Secondly, the absolute degree of risk in middle age, even for men with a combination of risk factors, is comparatively low. A man of 45 with both hypercholesterolaemia and diabetes has an $83.5 \%$ chance of surviving for the next 10 years, and a $92.5 \%$ chance of not dying of coronary heart disease in those 10 years. Finally, the lack of reversibility of risk with lowering of a risk factor ${ }^{5}$ may relate to damage already done but could also imply that the risk factor is an epiphenomenon indicating the presence of the underlying true pathogenic mechanism. If a high cholesterol concentration is merely a marker of, say, free radical damage, or blood pressure of intrauterine environment $^{34}$ less benefit would come from intervention than might be expected.

I thank Dr Rory Collins and the Antiplatelet Trialists' Collaboration Group for updating the meta-analyses on cholesterol and aspirin respectively; Dr Rory Collins, Professor Walter Willett, and Professor Michael Oliver for comments on previous drafts of the manuscript; and Ms Sara Stanner for preparing the manuscript and tables.

1 Anonymous. Prevention of coronary heart disease [editorial]. Lancet 1984; 899 .

2 Tsevat J, Weinstein MC, Williams LW, Tosteson ANA, Goldman L Expected gains in life expectancy from various coronary heart disease risk factor modifications. Circulation 1991;83:1194-201.

3 Taylor WC, Pass TM. Shepard DS, Komaroff AL. Cholesterol reduction and life expectancy. A model incorporating multiple risk factors. Ann Intern Med 1987;106:605-14.

4 Rothenberg R, Ford ES, Vartiainen E. Ischaemic heart disease prevention estimating the impact of interventions. I Clin Epidemiol 1992;45:21-9.

5 Collins R, Peto R, MacMahon S, Hebert P, Fiebach NH, Eberlein KA, et al. Blood pressure, stroke, and coronary heart disease. Part 2, short-term reductions in blood pressure: overview of randomised drug trials in their epidemiological context. Lancet 1990;335:827-38.
6 Holme I. An analysis of randomized trials evaluating the effect of cholesterol reduction on total mortality and coronary heart disease incidence. Circulation 1990;82:1916-24.

7 Muldoon MF, Manuck B, Matthews KA. Lowering cholesterol concentrations and mortality: a quantitative review of primary prevention trials. $B M \mathcal{J}$ 1990:301:309-14

8 Peto R, Yusuf S, Collins R. Cholesterol-lowering trial results in their epidemiologic context [abstract]. Circulation 1985;72:III-451.

9 Antiplatelet Trialists' Collaboration. Secondary prevention of vascular disease by prolonged antiplatelet treatment. BMF 1988;296:320-31.

10 Rosengren A, Welin L, Tsipogianni A, Wilhelmsen L. Impact of cardiovascular risk factors on coronary heart disease and mortality among middle aged diabetic men: a general population study. BMf 1989;299:1127-31.

11 Jarrett RJ, Shipley MJ. Mortality and associated risk factors in diabetes. Acta Endocrinol 1985;110(suppl 272):21-6.

12 Stamler J. Epidemiology, established major risk factors, and the primary $\overrightarrow{\overline{\vec{S}}}$ prevention of coronary heart disease. In: Parmley WW, Chatterjee K, eds. Cardiology. Philadelphia: Lippincott, 1987: 1-41.

13 Hypertension Detection and Follow-up Program Cooperative Research Group. Mortality findings for stepped-care and referred-care participants in the Hypertension Detection and Follow-up Program, stratified by other risk the Hypertension Detection and Foll
factors. Prev Med 1985;14:312-35.

14 Multiple Risk Factor Intervention Trial Research Group. Multiple risk factor intervention trial. Risk factor changes and mortality results. $\exists A M A$ ஸ 1982;248:1465-7.

15 Oliver MF. Might treatment of hypercholesterolaemia increase non-cardiac $\vec{\circ}$ mortality? Lancet 1991;337:1529-31.

16 Brett AS. Treating hypercholesterolemia. How should practising physicians $\overrightarrow{\vec{\omega}}$ interpret the published data for patients? N Engl F Med 1989;321:676-80.

17 Davey Smith G, Pekkanen J. Should there be a moratorium on the use of cholesterol lowering drugs? BMF 1992;304:431-4

18 Rose G, Hamilton PJS, Colwell L, Shipley MJ. A randomised controlled trial of anti-smoking advice: 10-year results. $f$ Epidemiol Community Health $\omega$ 1982;36:102-8.

19 Rogot E, Murray JL. Smoking and causes of death among US veterans: 16 years of observation. Public Health Rep 1980;95:213-22.

20 Brown G, Albers JJ, Fisher LD, Schaefer SM, Lin J-T, Kaplan C, et al. Regression of coronary artery disease as a result of intensive lipid-lowering therapy in men with high levels of apolipoprotein B. N Engl $\mathcal{f}$ Med $\vec{\omega}$
1990;323:1289-98.

21 SHEP Cooperative Research Group. Prevention of stroke by antihypertensive $\vec{\omega}$ drug treatment in older persons with isolated systolic hypertension. Final 응 results of the Systolic Hypertension in the Elderly Program (SHEP). IAMA 1991;265:3255-64.

22 Government Actuaries' Department. Interim life tables based on data for years $\mathcal{G}$ 1987-1989. London: HMSO, 1991.

23 British Medical Association, Royal Pharmaceutical Society of Great Britain. British national formulary. No 21. London: BMA-RPS, 1991.

24 Parving H-H. Impact of blood pressure and antihypertensive treatment on $\overrightarrow{0}$ incipient and overt nephropathy, retinopathy, and endothelial permeability $\omega$
in diabetes mellitus. Diabetes Care 1991;14:260-9.

25 Farnett $L$, Mulrow CD, Linn WD, Lucey CR, Tuley MR. The J-curve phenomenon and the treatment of hypertension. FAMA 1991;265:489-95.

26 D'Agostino RB, Belanger AJ, Kannel WB, Cruickshank JM. Relation of low diastolic blood pressure to coronary heart disease death in presence of myocardial infarction: the Framingham study. BMY 1991;303:385-9.

27 Warram JH, Laffel LMB, Valsania P, Christlieb AR, Krolewski AS. Excess mortality associated with diuretic therapy in diabetes mellitus. Arch Interm Med 1991;151:1350-6.

28 Thompson SG, Pocock SJ. Can meta-analyses be trusted? Lancet 1991;338: 흘 1127-30.

29 US Department of Health and Human Services. The health benefits of smoking cessation: a report of the Surgeon General, 1990. Atlanta: Centers for Disease Control, Office on Smoking and Health, 1990. (DHHS publication No (CDC) 90-8416.)

30 Yudkin JS. Hypertension and non-insulin-dependent diabetes-chicken, egg, tablets, or insulin resistance? $B M 7$ 1991;303:730-2.

31 Turner RC, Stratton IM, Holman RR, Frighi V. Prospective study of hypertension in type 2 diabetes: increased risk of cardiovascular complications and comparison of therapies. Diabetic Med 1991;8(suppl 1):41A

32 Medical Research Council Working Party. MRC trial of treatment of mild hypertension: principal results. $B M \mathcal{F}^{1}$ 1985;291:97-104.

33 Heller RF, Chinn S, Tunstall Pedoe HD, Rose G. How well can we predict 3

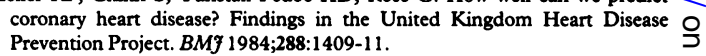

34 Barker DJP, Bull AR, Osmond C, Simmonds SJ. Fetal and placental size and N risk of hypertension in adult life. $B M F$ 1990;301:259-62.

(Accepted 4 March 1993)

\section{Correction}

Intraocular foreign body missed by radiography

An editorial error occurred in this lesson of the week by Andrena M McElvanney and Alistair R Fielder (17 April, pp 1060-1). The second sentence of the second paragraph should have read: "Ferrous ions destroy retinal photoreceptors and pigment epithelial cells (siderosis), and copper induces chalcosis."

\section{Diagnosis and treatment of malaria in Britain}

An authors' error resulted in an incorrect telephone number being 0 given in the appendix to this regular review by Malcolm Molyneux and Ray Fox (1 May, pp 1175-80). The correct number for the Liverpool School of Tropical Medicine is 0517089393. 